Sournals
INTERNATIONAL JOURNAL OF
ORGANIZATIONAL LEADERSHIP $\begin{gathered}\text { INDUSTRIAL } \\ \text { MANAGEMENT } \\ \text { INSTITUTE }\end{gathered}$

\title{
Structural and Behavioral Dimensions of Institutionalizing Methods of Organizational Culture Oriented on Human Munificence
}

\author{
Marziyeh Fardin ${ }^{1}$, Nour Mohammad Yaghoubi ${ }^{2 *}$ \\ ${ }^{1}$ MSc in Management, Faculty of Management, University of Sistan and Baluchestan, Zahedan, Iran \\ ${ }^{2}$ University of Sistan and Baluchestan, Zahedan, Iran
}

\begin{tabular}{l} 
Keywords: \\
Organizational Culture, \\
Human Munificence, \\
Institutionalizing, \\
Structural Dimension, \\
Behavioral Dimension \\
\hline Received \\
08 January 2016 \\
Received in revised form \\
28 July 2016 \\
Accepted \\
14 August 2016 \\
\hline
\end{tabular}

Correspondence:

yaghoubi@hamoon.usb.ac.ir

\begin{abstract}
According to general administrative policies which are imparted to government organizations, this paper is aimed to identify and prioritize the institutionalizing methods of organizational culture based on human munificence in structural and behavioral dimensions. This research is an applied research adopting a descriptive-correlational method and survey method. The statistical community of this study consisted of 341 employees of University of Sistan and Baluchestan and among them, 125 employees were randomly chosen. In order to collect data, a researcher-made questionnaire of organizational culture based on human munificence is used. The results of one sample t-test confirmed all identified factors in the model except one of them and this indicated that the mentioned factors can play a role in institutionalizing organizational culture based on human munificence. Finally, these factors were prioritized by using the Friedman test. The results indicated that meritocracy and performance evaluation in structural dimension and accountability. The properties' protection which is in behavioral dimension has the most priorities for institutionalizing the culture of human munificence-oriented in organizations.
\end{abstract}

(C)AIMI Journals

A deep look into the situation of organizations shows that despite all efforts and planning by the management of organizations, not all of them were achieve to the same level of success. The key success factors for any organization are complicated, silent, and hidden but extremely powerful and they can be considered as good drives for dynamic movements or advancement barriers. This phenomenon is referred to powerful organizational culture and plays an important role in controlling the internal configuration of employees' behavior, making a 
change in inappropriate behaviors, and stabilizing the targeted behaviors in the organizations. Also, this factor is a stable resource of competitive advantage, a key efficiency factor, and a strategic asset of the organization which increases the coordination and adaptability between the organization and environment (Aktas, Cicek, \& Kiyak, 2011; Zheng, Yang, \& Mclean, 2010). It is considered as a social reality which is formed by unique interactions of the organization's members (Zamini, Zamini, \& Barzegary, 2011). Organizational culture influences all aspects of an organization and its importance is so clear that the main task of leaders is considered as changing, evolving, and establishing appropriate cultural values (Nasiri-Pour, Reisie, Masoudi Asl, \& Nazari, 2013). Lack of attention to the organization's culture is a complicated and non-material phenomenon and at the same time, highly effective. If it does not lead to the organizational failure and achieving their objectives and landscapes, it at least will form many drawbacks in the organizational movement's path and it will waste many resources in order to solve the formed problems due to facing anticipated objectives with common culture of the organization (Piran, Parvar, \& Esmi, 2012). The most successful organizations have a culture which is consistent with the powerful ethical values that lead to understanding the organizations' activities and drive commitment in regard of organizations' missions and therefore enforce behavioral standards or guidelines (Rahimi \& Agha Babayi, 2013). One important element in the organizations is excellence-oriented organizational culture. In this culture, human resources are emphasized on organizational cares regarding the human factors. In this culture, besides concentration on the internal environment of the organization, human resources are considered as essential capital and the paramount organizational competitive advantage. Therefore, attention to human resources and manner of developing, managing, and directing them turns to the first issue of intelligent and dynamic organization. One element of excellence-oriented culture is human munificence and therefore employees are the main capital and the most important factor of strategic and competitive advantage. There is an emphasis on performing organizational actions based on the mutual respect and keeping munificence of employees in assigning responsibilities (Farahi Bouzjani et al., 2013). The importance of this munificence is significant when God started his inspiration in Quran through describing munificence, pointed out to his angels as munificence, glorified human being by describing munificence, and considered as a criterion and measure for human dominance (Rahmani Zarvandi,2010). Ethics are one of topics which its use is emphasized in Islamic society and can play an important role in managing the organizations effectively. Work discipline, affection, consulting, humbleness, keeping promises, serving, and affability are considered as some of appropriate ethical methods which are emphasized by Islam in managing the organizations. Preserving human munificence is an important approach for persistence in today's business environment which is often neglected. In this regard, establishing the ethical behaviors and human munificence in the organizations can enforce ethical behavior in the organizations; therefore, it will lead to decreasing discrimination, injustice, increasing the organizational spirit and commitment of employees, human development and excellence, inflorescence of organizations, and advancement of society (Askari Vaziri, Zarei Matin, \& Amiri, 2012; Nejad Salim, 2007). In addition, general policies and administrative systems which are announced to all governmental organizations point out initially to institutionalizing organizational culture based on human munificence and respecting to human resources. 
Locating this at the beginning of administrative policy papers shows the importance of this topic in macro-management of the country. Therefore, the objective of this research is identifying the institutionalization processes of organizational culture based on human munificence, specifying the current status of the university with regard to the indicators, prioritizing indicators, and finally providing some strategies for institutionalizing culture based on human munificence.

\section{Organizational Culture}

According to the current situation which focused on organizational systems' improvement, organizational culture is showed up as origin of all organizational capabilities and the ultimate success or failure of the organizations are heavily dependent on their culture (Sultani, 2012). This concept emerged in the late of 1970s and the early of 1980s for the first time and became as one of the most influential management concepts in different types of research (Linnenluecke \& Griffitths, 2010). In addition, the ethical behaviors can issue within the organizations because human being can find these beliefs and values within the organizational culture (Sefidchian \& Mojarab, 2013). Studying organizational culture of an organization is important because we can find the organization's weaknesses and differences between current and desirable situation from the viewpoint of that organization's employees (Salmani Nejad, Daneshvar, \& Mir Fakhrodini, 2012). Schein (2004) Kotter and Heskett (1992) defined organizational culture as a series of beliefs, values, and assumptions which are common among members of an organization (Gregory, Harris, Armenakis, \& Shook, 2009; Shahzad, Luqman, Rashid khan, \& Shabbir, 2012). Shahzad et al. (2012) considered organizational culture as a norm paste which keeps the whole organization together. Verhelst (1990) defined culture as different aspects of life such as technical knowledge, customs of food and clothes, thinking methods, values, language, symbols, social-political and economical behaviors, and method of decision-making. In addition, Hofstede (1991) defined culture as mind software and he argued that the culture provides a guide for human beings about the way of thinking. According to these definitions, culture has various manifestations which are counted as its elements. The most important elements of it include values, ideologies, norms, and symbols (Askari Vaziri, Zarei Matin, \& Amiri, 2012). Different models are provided for organizational culture; for example, Denison (1990) concentrated his efforts on developing a unified theory of culture and then identifying the extensive series of attributes and values which provides a comprehensive understanding and a deeper insight of culture. In 2000, he identified four dimensions of organizational culture which lead to organizational efficiency. These dimensions consist of involvement, consistency, adaptability, and four missions. These dimensions are offered as key factors of business (Yilmaz \& Ergun, 2008). Cameron and Quinn (1999) identified four types of culture in their model which included hierarchical culture, market culture, clan culture, and adhocracy culture. Clan culture, as a team-oriented culture, emphasizes on flexibility and internal concentration. Adhocracy oriented culture which is called as development and entrepreneurship culture emphasizes on high flexibility and competitive advantage. Market culture which is also called as rational culture emphasizes on the stability and control the competitive market positioning with the aim of high productivity. Finally, hierarchical culture emphasizes on internal stability and maintenance through precise setting of duty and executing 
severe rules (Azar \& Ali Pour Dervishi, 2011). All organizations probably have some properties for all four types of cultures (Sanjaghi, Akhavan, \& Ojaghi, 2013). They have nine major organizational variables in each type of cultures including the purpose of the organization, performance criteria, the power of the authority, power source, the decision making, leadership, compliance practices and acceptance, evaluation criteria, and motivating staff members. He believed that the culture of an organization with respect to these variables was identified in a cultural group (Ghorbani, Assadi, \& Sharifi, 2009). In this model, Brown divided the culture into four kinds of culture including bureaucratic culture, tribal culture, entrepreneurship culture, and the market culture. Looking at the model which are designed to study and explain the corporate culture emphasized on managing the human resources and the importance of their reproductive patterns such as partnership agreement, tribal culture, and corporate and mission.

\section{Human Munificence}

The munificence of human dignity means the right to have a dignified life in society without threatening him with the violence of their words and deeds. Respect for human society is considered as an accepted principle by Islam and much emphasis has been done on it. Human munificence is not only considered as a set of non-stripping and transferable rights, but also as basic human rights which leads to sustainable development in any society. If you do not pay attention to the values of justice and freedom, equality and peace has lost its meaning in international relations and therefore we saw injustice, violence, and discrimination. There are different point of views about the religious aspect of human munificence in which human dignity is considered as a holy man due to the dignity of a divine phenomenon. Immanuel Kant, a German philosopher, defined human munificence as the dignity and the value for all human which are essential for independence and moral capacity. Aramesh (2011) stated that people should always be considered as an end and never simply as a means. Munificence and human dignity are considered as a common denominator across all religions and schools. Human resources or human capital are considered as essential assets of any organization (Asnaashari, 2008). A model of human munificence provides fundamental criteria and values. They express the basic concepts and ideas of thinkers and scholars of organizations with modern management, objectives, compatibility, and adaptation. This model presents the main conditions for preserving the human's munificence model as a competitive advantage, believing, practicing these concepts throughout the organization particularly between managers, and expanding it among all employees. These concepts include security and safety, justice and integrity, ethics and honesty, empowerment, and increasing efficiency and effectiveness of learning. It is composed of four major criteria. The fundamental core and heart of this model provides a foundation for evaluating the organizations' staff to preserve the human munificence including mental and psychological variables such as personality and respect for others, behavioral variables such as responsibility, flexibility, ethical commitment, functional variables including consulting, creativity, purpose, and look for the future, and physical variables (Nejad Salim, 2007).

\section{The Review of Literature}


Research to study the situation and determine the attributes and indicators' of organizational culture had a long history. Sultani (2012) in their survey investigated corporate culture based on religious principles and Islamic values. The findings of this study showed that there were both positive and negative factors which influenced on the value and strength of corporate culture and on the other hand, on their weaknesses and damages. Optimal model is formed based on four types of native cultures including navy training based culture, knowledge culture, spiritual culture, and cultural relationship. Other studies attempted to design and provide the organizational culture. The results introduced five types of organizational culture school including change oriented, excellence oriented, idealistic oriented, and law oriented. Furthermore, according to the research, school's culture occupied the first place and transformation culture allocated the last place to itself (Farahi Bouzjani, Sanjagh, Bazargani, \& Soltani, 2013). The results of Rahmani Seresht and Saghravani’s study (2013). (2013) showed that the average components of organizational culture and professional ethics were more than the average of the components of organizational culture. Among the components of organizational culture, only risk taking and team orientation have the competence of forecasting professional ethics among organization' members and only the relationship between culture and human munificence is significant. Therefore, we concluded that organizational culture had a significant impact on the individual behavior, organizational performance, job motivation, creative and innovative population, and commitment and professional ethics. Askari Vaziri et al. (2012) identified the components of organizational culture with emphasis on the work of Da Nahj which determined them such as spirituality, learning, justice, sincerity, and conscious. The final pattern presents about 5 to 24 components of organizational culture which are necessary for keeping integrity of cultural institutions in organizations to include the development and human munificence, stability, convergence, compliance, flexibility and interaction, G-confidence, and communication missions.

Poursadegh (2013) studied the basic dimensions and parameters of organizational culture in the context of a national model based on research and designed models to assess the organizational culture. The results showed that there was a significant relation between size and parameters of organizational culture model. This model consists of five dimensions including structural, behavioral, cultural, contextual and each of them includes some parameters.

\section{Conceptual Framework}

According to the cultural characteristics of the Iranian society and religious teachings, organizational variables which determine the model of organizational culture and human munificence are recognized. In this study, two dimensions of organizational culture have been taken into the account. We have tried to focus on different features and elements of the culture including spiritual, educational, and anthropocentrism. Figure 1 shows the conceptual framework of the study based on literature and models of human munificence is presented. 


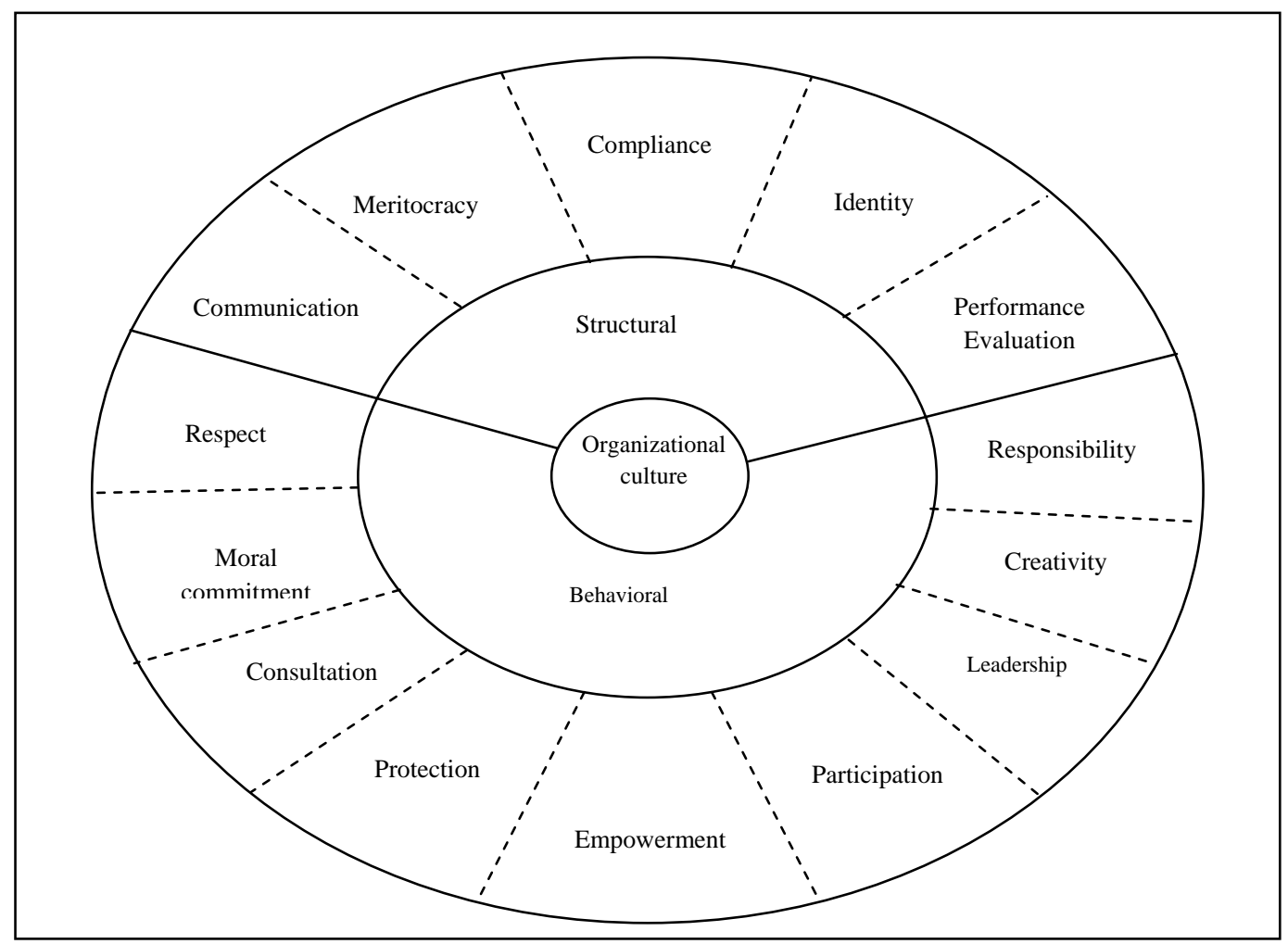

Figure 1. Conceptual framework

In humanitarian cultural, the behavioral section consists of elements such as moral commitment, respect, responsibility, creativity, leadership, participation, empowerment, protection, and consultation (Poursadeqh, 2013). Moral commitment refers to the promise or commitment for taking certain jobs, and pledge and compassion. Conscience and moral obligation have their roots in the human nature. Organizational commitment as a moral obligation is essential for personal and professional life of every human being (Salemi, 2014). Respect for human rights guards the value of human munificence and human authority. Moreover, responsibility is our duty to take the ownership for our decisions. Herbert Fox believed that the creative process is a process of thinking about any kind of problems and creativity usually presents the innovative and useful ways of solving the problems. Without cultivating the real sources of trust and honesty, creativity cannot flourish. People who work together, they should know that they can count on each other, and they can tell right and actually hear from their colleagues (Heidari, 2011). Koopman and Wierdsma (1998) emphasized on the participation in the process of making critical decisions or at least dominant criteria which impact on the decisions senior officials and staff. Empowerment means to empower and help people to develop a sense of self-esteem, motivate them to overcome their sense of powerlessness and helplessness (Miri, Sabzikaran, \& Rezaii, 2012). Public property refers to property that all people have the right to use and enjoy it; therefore, protecting this property seems to be essential. In this study, property points to the property that each member is responsible for protecting it. Finally, consultation as an intellectual work 
refers to the use of ratings, wisdom, knowledge and tastes of others, and learn from experts and people to present the ideas.

According to the conceptual framework, the second part which is structural index reflects in the bureaucratic culture and its elements include performance evaluation, communication, identity, meritocracy, and compliance (Poursadeqh, 2013). Performance evaluation refers to the systematic assessment of individuals when they carry out their assigned jobs or tasks for determining their potential for future growth and improvement. Communication is the process of transferring and exchanging information, ideas, concepts, and people's feelings in the organizations. Identity implies to the common understanding of employees of the nature of the organization to which they belong which originates from their knowledge about their organizations. In fact, this definition refers to a common understanding of members (Rahman seresht \& Saghravany, 2013). Meritocracy helps people to act properly in a democratic situation in accordance with the appropriate organizational abilities, capabilities and skills, and specialized professional qualifications. Compliance refers to the order of actions which should be expressed.

\section{Research Questions}

Based on the conceptual framework of this study, the following research questions are presented:

- What are the methods of institutionalization of organizational culture based on human munificence and upholding human capital?

- How are the prioritizing methods of institutionalization of organizational culture based on human munificence and upholding human capital?

- What are the mechanisms of institutionalization of organizational culture based on human munificence and upholding human capital?

\section{Method}

This study is an applied research adapting a descriptive-correlational method and survey design. The statistical population of this study consisted of 341 experts, professors, students, and graduates of Management and Economics faculty in Islamic Azad University of Sistan and Baluchestan. Random sampling was used to select the sufficient number of subjects for the study. The main instrument of the study was researcher-made questionnaire. Since no standard questionnaire was found on organizational culture based on human Munificence, a questionnaire including 61 statements was designed to measure 14 variables. The reliability of the questionnaire was estimated through using Cronbach's alpha $(\mathrm{R}=0.91)$. The content validity of the questionnaire was also confirmed by professors and experts of the field. In this research, Likert scale was used (strongly agree to strongly disagree). Figure 2 shows the qualitative identification of variables. This figure explicitly indicates that each variable is extracted from what source. 


Dimension
Behavioral
Dimension

Figure 2. Qualitative identification of variables

\section{Results}

Table 1 presents the demographic features of the participants such as gender, age, their education, academic degree, and field of study.

Table 1

The Descriptive Statistics of the Data by Demographic

\begin{tabular}{cccc}
\hline & Dimension & Frequency & Frequency Percent \\
\hline Sex & Man & 60 & $45 / 5$ \\
Age & Woman & 72 & $54 / 5$ \\
& Under 25 years & 38 & $28 / 8$ \\
& $30-25$ & 57 & $43 / 2$ \\
& $35-30$ & 18 & $13 / 6$ \\
Education & $40-35$ & 10 & $7 / 6$ \\
& Above 40 & 9 & $6 / 8$ \\
& Above Diploma & 5 & $3 / 8$ \\
& License & 90 & $68 / 2$ \\
Academic Degree & Above License & 18 & $13 / 6$ \\
& Ph.D. & 19 & $14 / 4$ \\
& MSc Student & 84 & $36 / 6$ \\
& PhD student & 12 & $9 / 1$ \\
& Assistant Professor & 19 & $14 / 4$ \\
& Associate Professor & 4 & 3 \\
Field of Study & Employee & 13 & $9 / 8$ \\
& Management & 74 & $56 / 1$ \\
& Theology & 47 & $35 / 6$ \\
& Economy & 6 & $4 / 5$ \\
& Other & 5 & $3 / 8$ \\
\hline
\end{tabular}


According to Table 1, the significant part of studied sample consists of females whose age ranges extend from 25 to 30 years old. The major of most of participants was management. To confirm the identified factors in the conceptual model based on the principles, one sample t-test was used. Table 2 presents the results one-sample t-test.

Table 2

Results of One-Sample T-Tests

\begin{tabular}{lcccc}
\hline & Mean & SD & T & Mean Difference \\
\hline Performance Appraisal & 4.37 & 0.58 & 27.05 & 1.37 \\
Communications & 4.3 & 0.6 & 24.84 & 1.3 \\
Identity & 3.92 & 0.59 & 17.85 & 0.92 \\
Meritocracy & 4.44 & 0.62 & 26.69 & 1.44 \\
Laws & 1.91 & 0.69 & -17.85 & -1.08 \\
Ethical Commitment & 4.19 & 0.78 & 17.56 & 1.19 \\
Respect & 4.26 & 0.5 & 28.54 & 1.26 \\
Responsibility Vulnerability & 4.36 & 0.53 & 29.48 & 1.36 \\
Creativity & 3.16 & 0.53 & 3.62 & 0.16 \\
Leadership & 4.11 & 0.57 & 22.3 & 1.11 \\
Partnership & 4.21 & 0.55 & 25.02 & 1.21 \\
Empowerment & 3.92 & 0.6 & 17.63 & 0.92 \\
Protection & 4.26 & 0.73 & 19.93 & 1.26 \\
Consultation & 4.21 & 0.57 & 24.45 & 1.21 \\
\hline
\end{tabular}

As Table 2 shows, the average of all indicators except for laws was more than the average in question. Therefore, there was significant relationship between the mean scores of all indicators and the mean of obtained scores which was more than the mean score of the questions. The respondents' reply to all indices has assessed well except for laws; and these factors can contribute to the institutionalization of organizational culture based on human munificence. Friedman's test was used to prioritize the indicators in two structural and behavioral dimensions. Table 3 presents the ranking results and significance level of Friedman's test for the behavioral dimension.

Table 3

Ranking Results \& Significance Level of Friedman's Test for the Behavioral Dimension of Organizational Culture

\begin{tabular}{lc}
\hline Indicators & Mean Rank \\
\hline Ethical Commitment & 5.66 \\
Respect & 5.76 \\
Responsibility -Vulnerability & 6.20 \\
Creativity & 1.65 \\
Leadership & 4.92 \\
Partnership & 5.47 \\
Empowerment & 4.03 \\
Protection of Property & 5.79 \\
Consultation & 5.53 \\
N & 132 \\
Chi-Square & 299.64 \\
Df & 8 \\
Asymp.Sig. & 0.00 \\
\hline
\end{tabular}


Table 4 represents the rating results and significance level of Friedman's test for structural dimension of organizational culture.

Table 4

Rating Results \& Significance Level of Friedman's Test for the Structural Dimension of Organizational Culture

\begin{tabular}{lc}
\hline Indicators & Mean Rank \\
\hline Performance Appraisal & 2.76 \\
Communications & 2.55 \\
Identity & 1.74 \\
Meritocracy & 2.95 \\
N & 132 \\
Chi-Square & 77.07 \\
Df & 3 \\
Asymp. Sig. & 0.00 \\
\hline
\end{tabular}

As it can be seen in Tables 3 and 4, the significance level (p-value) is less than 0.05; so that, it could be concluded that the indicators of organizational culture based on human munificence did not have the same priority in structural and behavioral dimensions.

\section{Discussion and Conclusion}

Organizational culture has a wide range of theories and models and has a great impact on the growth, dynamism, efficiency, and development of the organization. In this study, different aspects and dimensions of organizational culture were presented. The results of one sample ttest for the first research question confirmed that all identified factors except laws had a significant impact on the institutionalization of effective organizational culture based on human munificence. The results of this research were consistent with the previous studies of Hoseinian, Jafari, and Bahrami Nekoo (2010), Seyedi et al. (2014), Rahimi and Agha Babayi (2013)., and Azar and Ali Pour Dervishi (2011). These studies have examined the relationship between organizational culture and creativity, empowerment, ethics, and justice. All of them confirmed that there was a significant positive correlation between the variables. The results of the research have also consisted with the findings of Farahi Bouzjani et al. (2013), Sultani (2012), Poursadeqh (2013), and Askari vaziri et al. (2012). These studies provided templates based on religious values of the Islamic Revolution and have introduced the components such as human munificence, leadership, value-oriented, fundamentalism, justice, moral excellence, consultation, and meritocracy. Regarding the second research question, the results of Friedman's test revealed that two behavioral dimensions such as responsibility and protection and structural dimensions like meritocracy and evaluating the performance without considering law and regulations indices had the highest priority, respectively. This means that the respondents should consider more to these factors for institutionalizing the organizational culture based on human munificence.

The last research question is: "What are the mechanisms of institutionalization of organizational culture based on human munificence and upholding human capital? In order to improve the structural and behavioral dimensions of organizational culture based on human munificence, some recommendations are offered in the University of Sistan and Baluchestan. First, organizations should honor their responsible staff and provide an environment to expand 
creativity among their staff. Second, they should provide or create suitable conditions for participating their employees in the process of making decisions and use their ideas whenever they need. Third, they could give freedom to their employees to decide on how to achieve stable velocity. They further should respect their staff's ideas. Respectful treatment of managers with their employees helps them to develop strength points. Fifth, these organizations could provide and improve the culture of proper using and protecting of the assets by the employees. They could reduce the amount of accurate and predetermined instruction and recruit their employees based on their skills and qualifications. Finally, they should evaluate their employees' performances regularly and motivate them through promoting. Due to the fact that such research has not been held yet in public organizations of Zahedan or even in other provinces of the country, it cannot be compared with other studies and would be a new research in Iran. Obviously, this research has been conducted in the University of Sistan and Baluchestan and it must be checked in order to be generalized to other organizations

\section{References}

Acar, A. Z. (2012). Organizational culture, leadership styles, and organizational commitment in Turkish logistics industry. Procedia- Social \& Behavioral Sciences, 58, 217-226.

Aktas, E., Cicek, I., \& Kiyak, M. (2011). The effect of organizational culture on organizational efficiency: The moderating role of organizational environment and CEO values. Procedia Social \& Behavioral Sciences, 24, 1560-1573.

Aramesh, K. (2011). Human dignity in bio-medical ethics. Iranian Journal of Management Ethics, 4(3), 47-60.

Askari Vaziri, A., Zarei Matin, H., \& Amiri, A. N. (2012). Components of organizational Culture with an Islamic approach and emphasis on “Nahj Al Balaghah”. Quarterly Management in Islamic University, 1(3), 401-422.

Asnaashari, J. (2008). Topics application of modern management ( $1^{\text {st }}$ ed.). Tehran: Amirkabir Publication.

Azar, A., \& Ali Pour Dervishi, Z. (2011). Designing a model on the relationship of organizational culture and individual culture with justice perception of employees. Journal of Ethics in Science \& Technology, 5(3/4), 5-14.

Cameron, K. S., \& Quinn, R. E. (1999). Diagnosing and changing organizational culture. Reading: Addison-Wesley.

Denison, D. R. (1990). Corporate culture and organizational effectiveness. New York: John Wiley \& Sons.

Farahi Bouzjani, B., Sanjagh, M. E., Bazargani, M., \& Soltani, M. R. (2013). Designing and explanation model of cognition, evaluation, and organizational culture management (case study: one of Islamic Revolution institutions). Strategy Culture, 21, 113-138.

Ghorbani, M. H., Assadi, H., \& Sharifi, M. (2009). Relationship between organizational culture and effectiveness in the Iranian Physical Education Department based on the denison model. Kinetics Sciences \& Sports, 4, 107-118.

Gregory, B. T., Harris, S. G., Armenakis, A. A., \& Shook, C. L. (2009). Organizational culture and effectiveness: A study of values, attitudes, and organizational outcomes. Journal of Business Research, 62(7), 673-679.

Heidari, G. H. (2011). The culture of creativity and cultural creativity. Innovation \& Creativity in Human Science, 1(2), 57-88.

Hersey, P., \& Blunchard, K. (2005). Management of organizational behavior: Utilizing human resources (A. Alageband, Trans). Tehran: Amirkabir Publications.

Hoseinian, S., Jafari, M., \& Bahrami Nekoo, M. (2010). A study on the impact of organizational culture on empowerment of detectives in criminal investigations department of Tehran metropolitan police. Journal of Order \& Security Police, 3(3), 33- 57.

Hofstede, G. H. (1991). Cultures and organizations: Software of the mind. London: New York, McGraw-Hill.

Khairullah, D. H. Z., \& Khairullah, Z. Y. (2013). Cultural values and decision: Making in China. International Journal of Business, Humanities, \& Technology, 3(2), 1-12.

Koopman, P. L., \& Wierdsma, A. F. M. (1998). Participative management. In P. J. D. Doentu, H. Thierry, \& C. J. de-Wolf (Eds.), Personnel psychology: Handbook of Work and Organizational Psychology (pp. 297-324). England: Psychology Press/Erlbaum (UK) Taylor and Francis. 
Kotter, J. P., \& Heskett, J. L. (1992). Corporate culture and performance. New York: The Free Press.

Linnenluecke, M., \& Griffitths, A. (2010). Corporate sustainability and organizational culture. Journal of World Business, 45(4), 357-366.

Miri, A., Sabzikaran, A., \& Rezaii, H. (2012). The relationship between OCB and empowering employees. Improvement Management \& Development Study of Allameh Tabatabaii University, 21(67), 153-178.

Nasiri-Pour, A. A., Reisie, P., Masoudi Asl, I., \& Nazari, A. (2013). The relationship between organizational culture and intellectual capital of the Imam Khomeini Relief Committee Staff. Journal of Health, 7(1), 80-90.

Nejad Salim, A. (2007). Human munificence and the organization ( $1^{\text {st }}$ ed.). Tehran: Iran Training and Industrial Research.

Poursadegh, N. (2013). National model for organizational culture assessment. International Journal of Management Perspective, 1(3), 23-40.

Rahimi, H., \& Agha Babayi, R. (2013). Relationship between organizational culture and professional ethic, faculty members of Kashan University. Education Strategies in Medical Sciences, 6(2), 61-67.

Rahmani Seresht, H., \& Saghravani, S. (2013). Impact of organizational identity and orientation to work on the emotional commitment of employees. Journal of Change Management, 5(9), 52-67.

Salemi, A. (2014). Differences in organizational commitment and ethical commitment. Transport \& Development, 81, 83-84.

Salmani Nejad, R. A., Daneshvar, M., \& Mir Fakhrodini, H. (2012). Promotion organizational culture: The use of organizational excellence in Iran. The Journal of Management Improvement, 6(1), 128-152.

Sanjaghi, M. E., Akhavan, P., \& Ojaghi, H. (2013). Designing an interactive model for various cultures and processes involved in knowledge management. Journal of Research in Human Resource Management, 5(1), 23-42.

Seyedi, M., Shahidi, N., \& Shole, M. (2014). The relationship between organizational culture and organizational change creativity among elementary school principals in the district of Shiraz. Quarterly Journal of New Approaches in Educational Administration, 5(1), 39-54.

Shahzad, F., Luqman, R. A., Rashid khan, A. R., \& Shabbir, A. L. (2012). Impact of organizational culture on organizational performance: An overview. Interdisciplinary Journal of Contemporary Research in Business, 3(9), 975-985.

Sultani, M. (2012). Situation analysis and optimal design of corporate culture of organizations, armed forces based on religious principles and values of the Islamic Revolution. The Journal of Research in Islamic Management, 20(1), 99-122.

Verhelst, T. (1990). Life without roots. London: Zed Books.

Yilmaz, C., \& Ergun, E. (2008). Organizational culture and firm effectiveness: An examination of relative effects of culture traits and the balanced culture hypothesis in an emerging economy. Journal of World Business, 43, 290-306.

Zamini, S., Zamini, S., \& Barzegary, L. (2011). The relationship between organizational culture and job burnout among the professors and employees in the University of Tabriz. Procedia Social \& Behavioral Sciences, 30, 1964-1968.

Zheng, W., Yang, B., \& Mclean, G. N. (2010). Linking organizational culture, structure, strategy, and organizational effectiveness: Mediating role of knowledge management. Journal of Business Research 63(7), 763-771. 